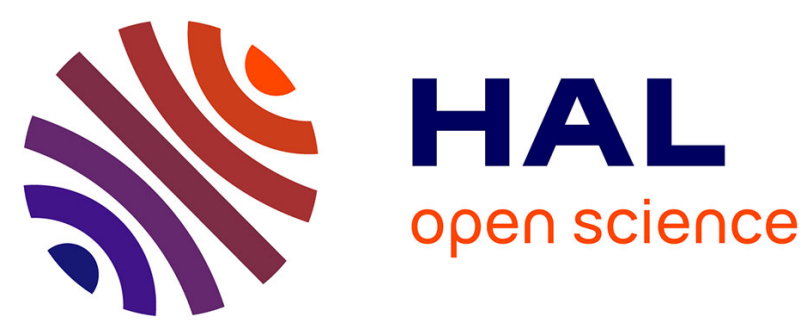

\title{
Martian Magmatic Clay Minerals Forming Vesicles: Perfect Niches for Emerging Life?
}

Jean-Christophe Viennet, Sylvain Bernard, Corentin Le Guillou, Violaine Sautter, Brian Grégoire, Albert Jambon, Sylvain Pont, Olivier Beyssac, Brigitte Zanda, Roger Hewins, et al.

\section{To cite this version:}

Jean-Christophe Viennet, Sylvain Bernard, Corentin Le Guillou, Violaine Sautter, Brian Grégoire, et al. Martian Magmatic Clay Minerals Forming Vesicles: Perfect Niches for Emerging Life?. Astrobiology, 2021, 21 (5), pp.605-612. 10.1089/ast.2020.2345 . hal-03370582

\section{HAL Id: hal-03370582 \\ https://hal.science/hal-03370582}

Submitted on 12 Oct 2021

HAL is a multi-disciplinary open access archive for the deposit and dissemination of scientific research documents, whether they are published or not. The documents may come from teaching and research institutions in France or abroad, or from public or private research centers.
L'archive ouverte pluridisciplinaire HAL, est destinée au dépôt et à la diffusion de documents scientifiques de niveau recherche, publiés ou non, émanant des établissements d'enseignement et de recherche français ou étrangers, des laboratoires publics ou privés. 


\section{Martian magmatic clay minerals forming vesicles: perfect niches for emerging life?}

Authors: Jean-Christophe Viennet ${ }^{1 *}$, Sylvain Bernard ${ }^{1}$, Corentin Le Guillou ${ }^{2}$, Violaine Sautter ${ }^{1}$, Brian Grégoire ${ }^{3}$, Albert Jambon ${ }^{1}$, Sylvain Pont ${ }^{1}$, Olivier Beyssac ${ }^{1}$, Brigitte Zanda ${ }^{1}$, Roger

\section{Affiliations:}

${ }^{1}$ Muséum National d'Histoire Naturelle, Institut de Minéralogie, Physique des Matériaux et Cosmochimie, CNRS UMR 7590, Sorbonne Université, CNRS, F-75005 Paris, France ${ }^{2}$ Univ. Lille, CNRS, INRA, ENSCL, UMR 8207 - UMET - Unité Matériaux et Transformations, F-59000 Lille, France

${ }^{3}$ CNRS (Centre National de la Recherche Scientifique), Université de Poitiers, UMR 7285 IC2MPHydrasa, 5 rue Albert Turpain, Bâtiment B8, TSA 51106, 86073 Poitiers CEDEX 9, France;

*Correspondence to: J.-C. Viennet, e-mail: jean.christophe.viennet25@gmail.com

\section{Abstract:}

Mars has been habitable in its early history but the consensus is that it is quite inhospitable today, in particular because its modern climate cannot support stable liquid water at the surface. Here we report the presence of magmatic Fe/Mg clay minerals within the mesostasis of the Martian meteorite NWA5790, an unaltered 1.3 Ga nakhlite archetypal of the Martian crust. These magmatic clay minerals exhibit a vesicular texture forming a network of micro-cavities/pockets which could serve as micro-reactors allowing molecular crowding, a necessary step for the emergence of life. Because their formation does not depend on climate, such niches for emerging life may have been generated on Mars at many periods of its history, whatever the stability/availability of liquid water at the surface. 
The concept of habitability is essentially tied to the presence of liquid water at (or near) the surface of a planetary body. The surface of Mars has been habitable during the Noachian (4.1 3.7 Ga) because liquid water was then both stable and available, at least episodically. Environments likely existed on the Noachian Mars with liquid water and metabolic energy sources available for the development of life (Westall et al., 2013; Grotzinger et al., 2014; Kral et al., 2014; Hurowitz et al., 2017; McMahon et al., 2018). This view relies on the widespread occurrence of Noachian $\mathrm{Fe} / \mathrm{Mg}$ clay minerals interpreted as products of the alteration of pre-existing silicates by (sub)surface liquid water (Bibring et al., 2006; Ehlmann et al., 2011; Carter et al., 2013; Sun and Milliken, 2015; Viennet et al., 2019). But this may not be the entire story. In fact, some clay minerals can directly precipitate from magmatic fluids (Meunier et al., 2008, 2012; Berger et al., 2014, 2018; Viennet et al., 2020). Because these minerals cannot be used as a proxy for the past presence of liquid water, it seems a priori difficult to consider such magmatic clay minerals as indicators of habitability. Still, as discussed here, magmatic clay minerals may offer fantastic opportunities for prebiotic reactions.

To date, the only occurrence of Martian magmatic Fe/Mg clay minerals has been found in the evolved (alkali/felsic) mesostasis of Nakhla (Viennet et al., 2020), the Martian meteorite eponym for nakhlites. Whether or not these minerals are more than anecdotal on Mars is difficult to determine, especially given the fierce debate over the exact fraction of the Martian crust made up of evolved (alkali/felsic) rocks (Sautter et al., 2016; Udry et al., 2018; Bouley et al., 2020). Here we report the presence of magmatic Fe/Mg clay minerals within the mesostasis of NWA5790, an unaltered Amazonian nahklite ( 1.3-1.4 Ga - Nyquist et al., 2001). In contrast to that of Nakhla, 

the mesostasis of NWA5790 does not exhibit a high level of igneous differentiation, making this meteorite more archetypal of the Martian crust (Udry et al., 2018).

\section{Materials and Methods}

\subsection{Section of NWA5790 investigated}

The section of NWA 5790 investigated here is the section B described in Jambon et al. (2016). This section was selected because it does not exhibit any trace of terrestrial alteration (Jambon et al., 2016) nor "desert varnish" or "caliche", i.e. clay mineral sheets or calcite veins produced by alteration (Tomkison et al., 2015; Balta et al., 2017). The augite and olivine grains of the section investigated do not display any iddingsite, amphibole or smectite vein (see figure S1).

\subsection{Scanning and Transmission Electron Microscopy}

Scanning electron microscopy (SEM) was performed on a thin section of Nakhla using a SEMFEG Ultra 55 Zeiss (IMPMC - Paris, France) microscope operating at a 15-kV accelerating voltage and a working distance of $7.5 \mathrm{~mm}$ for imaging with backscattered electrons and energy dispersive X-ray spectroscopy (EDXS) mapping. Transmission electron microscopy in scanning mode (STEM) was performed on FIB foils using a Thermofisher Titan Themis 300 microscope operated at $300 \mathrm{keV}$ (CCM - Lille, France). TEM-based hyperspectral EDXS data (see below) were obtained using the super-X detector system comprising four windowless silicon drift detectors of high sensitivity. The probe current was set at maximum $200 \mathrm{pA}$ with a dwell time at $10 \mu$ s per pixel. 


\subsection{Focused ion beam preparations} Focused ion beam (FIB) ultrathin sections were extracted using an FEI Strata DB 235 (IEMN, Lille, France). Milling at low Ga-ion currents minimises common artefacts including local gallium implantation, mixing of components, creation of vacancies or interstitials, creation of amorphous layers, local compositional changes or redeposition of the sputtered material on the sample surface(Wirth, 2009).

\subsection{EDXS data processing}

A key aspect of this work is the post-processing of the collected EDXS hyperspectral data, performed using the Hyperspy python-based package(De La Pena, Francisco et al., 2017). The signal was first denoised using PCA and then fitted by a series of Gaussian functions. The integrated intensities of the Gaussian functions were used to quantify the spectra thanks to the Cliff-Lorimer method, using experimentally determined k-factors. Special care was taken to correct for absorption effect within the sample, in particular for oxygen X-rays. Absorption correction depends on thickness density, which can be determined by comparing quantification made by Iron L-lines and Iron K-lines(Morris, 1980). Each pixel was quantified independently, and end-member phases were identified based on mixing diagrams.

\subsection{Raman spectroscopy}

Raman was performed using a homemade time-resolved Raman spectrometer (Beyssac et al., 2017). The laser is a nanosecond pulsed DPSS laser operating at $532 \mathrm{~nm}$ with a $1.2 \mathrm{~ns}$ duration (FWHM) for the pulse, 10 to $2000 \mathrm{~Hz}$ repetition rate and up to $1 \mathrm{~mJ}$ output energy per pulse. The laser was focused at the sample surface through a microscope objective (x20, numerical aperture 0.42 ) and the Raman signal was collected in the backscattering geometry. A Notch filter was 
used to cut the Rayleigh scattering. The signal was collected in an optical fiber and sent into a modified Czerny-Turner spectrometer manufactured by Princeton Instrument to be measured using a PIMAX4 ICCD camera manufactured by Princeton Instrument.

\section{Results}

Like the other nakhlites, NWA5790 is an unaltered cumulate rock exhibiting large euhedral/subhedral crystals of augite that are set in a crystalline mesostasis (Fig 1 and 1S). Consistent with previous reports (Tomkinson et al., 2015; Jambon et al., 2016; Balta et al., 2017), petrographic observations show that the mesostasis of NWA5790 is made of Na/Caplagioclases and K-feldspars embedding skeletal Fe-rich Ti-oxides and Ti-rich magnetites hosting ilmenite exsolutions (Fig 1). In addition to augite grains, the investigated section contains an unaltered euhedral olivine (Fig. S1) and a zone of about the same size composed of fibrous minerals (Fig 1). This zone exhibits a radial structure, with a central pore of about $200 \mu \mathrm{m}$ in diameter, surrounded by Fe/Mg clay minerals intimately mixed with Fe-Si-Al-Ca nanograins, themselves surrounded by dendrites of maghemite and rather amorphous Fe-Si-AlCa materials in contact with augite grains and the mesostasis (Fig 1 and supplementary infos). In contrast to the contact with augite grains, the transition with the mesostasis is not sharp, some $\mathrm{Na} / \mathrm{Ca}$ plagioclases and skeletal equiaxed Fe-rich Ti oxides are distributed within the observed dendrites. These dendrites display a nearly paraboloidal finger-like shape with side-branches, i.e. a columnar dendritic texture with trunks of a few to hundreds of microns in length (Fig 2), typical of sudden cooling/quenching conditions.

The Fe/Mg clay minerals consist of layers of a few hundreds of nanometers in length stacked over a few tens of nanometers, with layer to layer distances of $\sim 11.8 \AA$, a typical structure of 
smectites (Fig 3). These Fe/Mg clay minerals are chemically heterogeneous, with a mean chemical composition falling between nontronite, celadonite and saponite (Fig 3). Most importantly, the observed anti-correlation between $\mathrm{Mg}$ and $\mathrm{Cl}$ (Fig. 3) attests to the presence of

\section{Discussion}

These Fe/Mg clay minerals have clearly not been produced via the aqueous alteration of preexisting silicates. In fact, the section of NWA5790 investigated here has been recognised to be unaltered (Tomkinson et al., 2015; Jambon et al., 2016) and the alteration of the Ti-rich and Alrich mesostasis (mainly made of feldspars) would have produced Ti-rich and Al-rich secondary minerals (Meunier and Velde, 2004). In contrast, the clay minerals described here display a low $\mathrm{Al}$ content (4 wt.\%) and do not contain any Ti. The Fe and $\mathrm{Mg}$ contents of these clay minerals could be consistent with the alteration of augite, but none of the augite grains of NWA5790 displays alteration textures such as retreating surfaces or pitch-like features resulting from dissolution and no contact with the Fe/Mg clay minerals could be observed. Plus, the high $\mathrm{Cl}$ content of these $\mathrm{Fe} / \mathrm{Mg}$ clay minerals is similar to those of Cl-rich magmatic apatites, scapolites and amphiboles found in other nakhlites (Sautter et al., 2006; McCubbin et al., 2013; Giesting and Filiberto, 2016) and to that of the magmatic Fe/Mg clay minerals found in Nakhla (Viennet et al., 2020). 
The subhedral/euhedral nature of augite crystals is consistent with slow growth within a magmatic chamber (Treiman, 2005; Jambon et al., 2016; Udry and Day, 2018) or within a chilled margin of a lava flow/sill (Tomkinson et al., 2015). The crystallisation and the accumulation of augite grains led to the entrapment of a residual liquid enriched in $\mathrm{Cl}$, potentially as a result of contamination by an exogenous Cl-rich fluid (McCubbin et al., 2013; Udry and Day, 2018). With decreasing temperature, the $\mathrm{Na} / \mathrm{Ca}$ plagioclases and the $\mathrm{K}$-feldspars crystallised together with the skeletal equiaxed Fe-Ti oxides and the skeletal Ti-magnetites, eventually leading to the exsolution of a $\mathrm{Cl} / \mathrm{Fe}$-rich brine (Fig 1). Here, the screw dislocations at the surface of the augite grains (together with the decrease of solubility of Fe III with decreasing temperature) potentially controlled the very fast precipitation of the observed dendrites, explaining their screw shapes and unidirectional solidification structures (Vernon, 2004). Masses of highly porous $\mathrm{Cl}$-bearing $\mathrm{Fe} / \mathrm{Mg}$ clay minerals then precipitated from the residual brine (together with or right before the Fe-Si-Al-Ca nanograins), i.e. before reaching a high level of igneous differentiation in contrast to what occurred in Nakhla (Viennet et al., 2020). The magmatic production of $\mathrm{Fe} / \mathrm{Mg}$ clay minerals evidenced here in a Martian meteorite archetypal of the Martian crust portends that a possibly significant fraction of the Fe/Mg clay minerals detected on Mars so far may not be the products of the aqueous alteration of preexisting silicates by (sub)surface water, questioning a priori the past habitability of Mars. Yet, the magmatic $\mathrm{Fe} / \mathrm{Mg}$ clay minerals described here have chemical and physical properties offering fantastic opportunities for (prebiotic) organic reactions (Russell and Martin, 2004; Duval et al., 2020). In fact, in addition to enabling electron transfer, their high Fe content may promote the synthesis and breakdown of universal metabolic precursors (Stucki, 2006), while their high $\mathrm{Mg}$ 
content may prompt both ribozyme catalysed and non-enzymatic RNA copying reactions (Adamala and Szostak, 2013).

Clay minerals have long been suggested as the perfect means of concentrating organic molecules onto their external surfaces and within their interlayer space so as to be available for prebiotic reactions (Bernal, 1951; Ferris and Ertem, 1992; Brack, 2013; Lagaly et al., 2013; Theng, 2018). The surface areas of the magmatic Fe/Mg clay minerals described here are very high: external and internal surface areas reach $30 \mu \mathrm{m}^{2}$ and $670 \mu \mathrm{m}^{2}$ per $\mu \mathrm{m}^{3}$, respectively (cf supplementary infos). For smectites, this corresponds to $2.4 \times 10^{14}$ external sites and $5.8 \times 10^{14}$ internal sites of possible interactions with organic functional groups (cf supplementary infos).

Most importantly, the vesicular texture of these magmatic Fe/Mg clay minerals form a network of chemically heterogeneous micro-cavities/pockets, offering even more optimal conditions for (prebiotic) organic reactions. In fact, most scenarios of the origin of life requires boundaries/membranes (either organic or inorganic) to isolate, concentrate and protect organic compounds that could eventually interact/react with each other (Szostak et al., 2001; Hanczyc, 2003; Chen and Walde, 2010; Sun et al., 2016). Plus, a boundary is a privileged interface for the formation of gradients which can promote organic reactions and could be exploited as an energetic source (Monnard and Walde, 2015; Branscomb et al., 2017; Branscomb and Russell, 2019). Here, more than 600 micro-cavities/pockets can be counted per $\mu \mathrm{m}^{2}$ of clay minerals, with surfaces ranging from $1.10^{-5}$ to $1.4 \cdot 10^{-2} \mu \mathrm{m}^{2}$ (Fig 4.C), each of them being potentially a distinct micro-reactor for organic chemistry. The multiple connections between these microcavities/pockets may allow organic molecules to diffuse freely into or out these microsystems, possibly leading to molecular crowding, thereby increasing the probability of achieving prebiotic chemical reactions. 


\section{Conclusion}

The section of the Martian nakhlite NWA5790 investigated here contains a zone composed of magmatic $\mathrm{Fe} / \mathrm{Mg}$ clay minerals mixed with $\mathrm{Fe}-\mathrm{Si}$-Al-Ca nanograins surrounded by dendritic maghemite. These magmatic Fe/Mg clay minerals exhibit a vesicular texture forming a network of micro-cavities/pockets which could serve as micro-reactors for the emergence of life. The fact that the formation of such niches for emerging life can be achieved via the magmatic precipitation of $\mathrm{Fe} / \mathrm{Mg}$ clay minerals should make these aggregates a focus for research into the origin of life, especially as such magmatic Fe/Mg clay minerals form within liquid-water-poor environments (prebiotic reactions are thermodynamically out of equilibrium in aqueous solution - Lambert, 2008). In fine, by evidencing the formation of niches for emerging life on Mars even during the Amazonian, the present study provides a strong rationale for the possible emergence of life on other planetary bodies, including rocky and/or icy ones (such as Ceres, Enceladus or Europa) on which the production of clay minerals has recently been reported (Waite et al., 2017; Marchi et al., 2019).

\section{References and Notes}

Adamala, K., Szostak, J.W. (2013) Nonenzymatic Template-Directed RNA Synthesis Inside Model Protocells. Science 342, 1098-1100.

Bailey, S.W. (ed.) (1984) Micas. De Gruyter.

Balta, J.B., Sanborn, M.E., Mayne, R.G., Wadhwa, M., McSween, H.Y., Crossley, S.D. (2017) Northwest Africa 5790: A previously unsampled portion of the upper part of the nakhlite pile. Meteoritics \& Planetary Science 52, 36-59.

Berger, G., Beaufort, D., Antoine, R. (2018) Clay minerals related to the late magmatic activity of the Piton des Neiges (Réunion Island): consequence for the primitive crusts. Clay Minerals 53, 675-690. 
Berger, G., Meunier, A., Beaufort, D. (2014) Clay mineral formation on Mars: Chemical constraints and possible contribution of basalt out-gassing. Planetary Geology Field Symposium, Kitakyushu, Japan, 2011: Planetary Geology and Terrestrial Analogs 95, $25-32$.

Bernal, J.D. (1951) The physical basis of life. Routledge and Paul, London.

Beyssac, O. et al. (2017) Nanosecond Time-Resolved Raman and Fluorescence Spectroscopy: Insights for Mineral and Organics Characterization. Lunar and Planetary Science Conference 2017 48, 1545.

Bibring, J.-P. et al. (2006) Global Mineralogical and Aqueous Mars History Derived from OMEGA/Mars Express Data. Science 312, 400.

Bouley, S. et al. (2020) A thick crustal block revealed by reconstructions of early Mars highlands. Nature Geoscience.

Brack, A. (2013) Clay Minerals and the Origin of Life. Developments in Clay Science. Elsevier, $507-521$.

Branscomb, E., Biancalani, T., Goldenfeld, N., Russell, M. (2017) Escapement mechanisms and the conversion of disequilibria; the engines of creation. Physics Reports 677, 1-60.

Branscomb, E., Russell, M.J. (2019) Why the Submarine Alkaline Vent is the Most Reasonable Explanation for the Emergence of Life. BioEssays 41, 1800208.

Carter, J., Poulet, F., Bibring, J.-P., Mangold, N., Murchie, S. (2013) Hydrous minerals on Mars as seen by the CRISM and OMEGA imaging spectrometers: Updated global view. Journal of Geophysical Research: Planets 118, 831-858.

Chen, I.A., Walde, P. (2010) From Self-Assembled Vesicles to Protocells. Cold Spring Harbor Perspectives in Biology 2, a002170-a002170.

De La Pena, Francisco, F. et al. (2017) Electron Microscopy (Big and Small) Data Analysis With the Open Source Software Package HyperSpy. Microscopy and Microanalysis 23, 214 215.

Duval, S. et al. (2020) On the why's and how's of clay minerals' importance in life's emergence. Applied Clay Science 195, 105737.

Ehlmann, B.L., Mustard, J.F., Murchie, S.L., Bibring, J.-P., Meunier, A., Fraeman, A.A., Langevin, Y. (2011) Subsurface water and clay mineral formation during the early history of Mars. Nature 479, 53.

Ferris, J., Ertem, G. (1992) Oligomerization of ribonucleotides on montmorillonite: reaction of the 5'-phosphorimidazolide of adenosine. Science 257, 1387-1389. 
Giesting, P.A., Filiberto, J. (2016) The formation environment of potassic-chloro-hastingsite in the nakhlites MIL 03346 and pairs and NWA 5790: Insights from terrestrial chloroamphibole. Meteoritics \& Planetary Science 51, 2127-2153.

Grotzinger, J.P. et al. (2014) A Habitable Fluvio-Lacustrine Environment at Yellowknife Bay, Gale Crater, Mars. Science 343, 1242777-1242777.

Hanczyc, M.M. (2003) Experimental Models of Primitive Cellular Compartments: Encapsulation, Growth, and Division. Science 302, 618-622.

Hurowitz, J.A. et al. (2017) Redox stratification of an ancient lake in Gale crater, Mars. Science 356 , eaah6849.

Jambon, A., Sautter, V., Barrat, J.-A., Gattacceca, J., Rochette, P., Boudouma, O., Badia, D., Devouard, B. (2016) Northwest Africa 5790: Revisiting nakhlite petrogenesis. Geochimica et Cosmochimica Acta 190, 191-212.

Kral, T.A., Birch, W., Lavender, L.E., Virden, B.T. (2014) Potential use of highly insoluble carbonates as carbon sources by methanogens in the subsurface of Mars. Planetary and Space Science 101, 181-185.

Lagaly, G., Ogawa, M., Dékány, I. (2013) Chapter 10.3 - Clay Mineral-Organic Interactions. In: Bergaya, F., Lagaly, G. (eds) Developments in Clay Science. Elsevier, 435-505.

Lambert, J.-F. (2008) Adsorption and Polymerization of Amino Acids on Mineral Surfaces: A Review. Origins of Life and Evolution of Biospheres 38, 211-242.

Marchi, S. et al. (2019) An aqueously altered carbon-rich Ceres. Nature Astronomy 3, 140.

McCubbin, F.M., Elardo, S.M., Shearer, C.K., Smirnov, A., Hauri, E.H., Draper, D.S. (2013) A petrogenetic model for the comagmatic origin of chassignites and nakhlites: Inferences from chlorine-rich minerals, petrology, and geochemistry. Meteoritics \& Planetary Science 48, 819-853.

McMahon, S. et al. (2018) A Field Guide to Finding Fossils on Mars. Journal of Geophysical Research: Planets 123, 1012-1040.

Meunier, A., Mas, A., Beaufort, D., Patrier, P., Dudoignon, P. (2008) Clay minerals in basalthawaiite rocks from Mururoa Atoll (French Polynesia). II. Petrography and geochemistry. Clays and Clay Minerals 56, 730-750.

Meunier, A., Petit, S., Ehlmann, B.L., Dudoignon, P., Westall, F., Mas, A., El Albani, A., Ferrage, E. (2012) Magmatic precipitation as a possible origin of Noachian clays on Mars. Nature Geoscience 5, 739.

Meunier, A., Velde, B.D. (2004) Illite: Origins, Evolution and Metamorphism. Springer-Verlag, Berlin Heidelberg. 
Monnard, P.-A., Walde, P. (2015) Current Ideas about Prebiological Compartmentalization. Life $5,1239-1263$.

Morris, P.L. (1980) The correction of thin foil microanalysis data for X-ray absorption effects. Electron Microscopy and Analysis 1979. The Institute of Physics 413-416.

Nyquist, L.E., Bogard, D.D., Shih, C.-Y., Greshake, A., Stöffler, D., Eugster, O. (2001) Ages and Geologic Histories of Martian Meteorites. In: Kallenbach, R., Geiss, J., Hartmann, W.K. (eds) Chronology and Evolution of Mars. Springer Netherlands, 105-164.

Russell, M.J., Martin, W. (2004) The rocky roots of the acetyl-CoA pathway. Trends in Biochemical Sciences 29, 358-363.

Sautter, V. et al. (2016) Magmatic complexity on early Mars as seen through a combination of orbital, in-situ and meteorite data. Lithos 254, 36-52.

Sautter, V., Jambon, A., Boudouma, O. (2006) Cl-amphibole in the nakhlite MIL 03346: Evidence for sediment contamination in a Martian meteorite. Earth and Planetary Science Letters 252, 45-55.

Stucki, J.W. (2006) Chapter 8 Properties and Behaviour of Iron in Clay Minerals. Developments in Clay Science. Elsevier, 423-475.

Sun, S., Li, M., Dong, F., Wang, S., Tian, L., Mann, S. (2016) Chemical Signaling and Functional Activation in Colloidosome-Based Protocells. Small 12, 1920-1927.

Sun, V.Z., Milliken, R.E. (2015) Ancient and recent clay formation on Mars as revealed from a global survey of hydrous minerals in crater central peaks. Journal of Geophysical Research: Planets 120, 2293-2332.

Szostak, J.W., Bartel, D.P., Luisi, P.L. (2001) Synthesizing life. Nature 409, 387-390.

Theng, B.K.G. (2018) Clay mineral catalysis of organic reactions. CRC Press, Taylor \& Francis Group, Boca Raton.

Tomkinson, T., Lee, M.R., Mark, D.F., Dobson, K.J., Franchi, I.A. (2015) The Northwest Africa (NWA) 5790 meteorite: A mesostasis-rich nakhlite with little or no Martian aqueous alteration. Meteoritics \& Planetary Science 50, 287-304.

Treiman, A.H. (2005) The nakhlite meteorites: Augite-rich igneous rocks from Mars. Geochemistry 65, 203-270.

Udry, A., Day, J.M.D. (2018) 1.34 billion-year-old magmatism on Mars evaluated from the cogenetic nakhlite and chassignite meteorites. Geochimica et Cosmochimica Acta 238, 292315. 
Udry, A., Gazel, E., McSween Jr., H.Y. (2018) Formation of Evolved Rocks at Gale Crater by Crystal Fractionation and Implications for Mars Crustal Composition. Journal of Geophysical Research: Planets 123, 1525-1540.

Vernon, R.H. (2004) A Practical Guide to Rock Microstructure. Cambridge University Press, Cambridge.

Viennet, J.-C. et al. (2020) Tardi-magmatic precipitation of Martian Fe/Mg-rich clay minerals via igneous differentiation. Geochemical Perspectives Letters 47-52.

Viennet, J.-C., Bultel, B., Werner, S.C. (2019) Experimental reproduction of the martian weathering profiles argues for a dense Noachian CO2 atmosphere. Chemical Geology $525,82-95$.

Waite, J.H. et al. (2017) Cassini finds molecular hydrogen in the Enceladus plume: Evidence for hydrothermal processes. Science 356, 155-159.

Westall, F., Loizeau, D., Foucher, F., Bost, N., Betrand, M., Vago, J., Kminek, G. (2013) Habitability on Mars from a Microbial Point of View. Astrobiology 13, 887-897.

Wirth, R. (2009) Focused Ion Beam (FIB) combined with SEM and TEM: Advanced analytical tools for studies of chemical composition, microstructure and crystal structure in geomaterials on a nanometre scale. Chemical Geology 261, 217-229. 


\section{Acknowledgments}

We thank Elisabeth Malassis for administrative simplification, the Atelier and the Cellule Projet (IMPMC) for the construction of the time-resolved Raman instrument @ IMPMC, David Troadec (IEMN) for the extraction of FIB foils, Imène Esteve (IMPMC) for her expert support with the SEM @ IMPMC, and Jean Michel Guigner (IMPMC) for his expert support with the TEM@ IMPMC. The authors would like to thank the collection of the Muséum National d'Histoire Naturelle for sharing the section of NWA 5790. The authors wish to acknowledge the Editor Dr. S.L. Cady, the associate editor C. McKay as well as two anonymous reviewers, for their constructive comments that greatly improved the quality of this work.

\section{Author Contributions}

JCV and SB designed the present study. JCV and SB conducted the SEM experiments. JCV and OB conducted the Raman experiments. JCV, SB and CLG conducted the TEM experiments. JCV and CLG performed SEM and TEM data reduction. All authors contributed to the interpretation of the results. JCV and SB wrote the manuscript, with critical inputs from all authors.

\section{Author Disclosure Statement}

No competing financial interests exist.

\section{Funding Information}

The SEM facility @ IMPMC is supported by Region Ile de France grant SESAME Number I-07593/R, INSU-CNRS, INP-CNRS and UPMC-Paris 6, and by the Agence Nationale de la Recherche (ANR) grant number ANR-07-BLAN-0124-01. The TEM facility @ Lille University is supported by the Chevreul Institute, the European FEDER and Région Nord-Pas-de-Calais. 
Fig. 1. SEM image of the zone of NWA 5790 investigated in BSE mode (A) and the corresponding EDXS-based mineralogical map (B). Note the euhedral augite grains with no dissolution features surrounding the dendritic maghemite and $\mathrm{Fe} / \mathrm{Mg}$ clay minerals.

Fig. 2. Dendritic structures. (A) BSE image of the Maghemite showing the location of the FIB foil shown in D-E. (B) Time-resolved Raman spectra of the Maghemite. (C) SEM image highlighting the dendritic texture of the maghemite. (D-E) TEM images in STEM mode of the FIB section showing the screw shape of the denditric texture along the main direction and their texture in spiral perpendicularly to the main direction.

Fig. 3. Magmatic Fe/Mg clay minerals. (A) SEM image in BSE mode showing the huge mass of clay minerals. (B). SEM image in BSE mode showing the fibrous texture of the clay minerals. (C) TEM image in STEM mode of the FIB section (location shown in Fig. S2) showing the contact between $\mathrm{Fe} / \mathrm{Mg}$ clay minerals and non-altered silicates. (D) TEM image in bright field showing the classical structure in sheets of the Fe/Mg clay minerals with a d-spacing of $11.7 \AA$. (E) Diagram showing the chemical composition of the $\mathrm{Fe} / \mathrm{Mg}$ clay minerals and indicating a mixture of nontronite, celadonite and saponite (left) and plot showing the $\mathrm{Mg}$ content as a function of $\mathrm{Cl}$ content (right).

Fig. 4. Magmatic Fe/Mg clay minerals. (A) TEM image in STEM mode showing the vesicles formed by the Fe/Mg clay minerals. (B) Size distribution of the vesicles corresponding to the TEM images in STEM mode (E). (C-E). TEM images in STEM mode showing the vesicles formed by the $\mathrm{Fe} / \mathrm{Mg}$ clay minerals. 


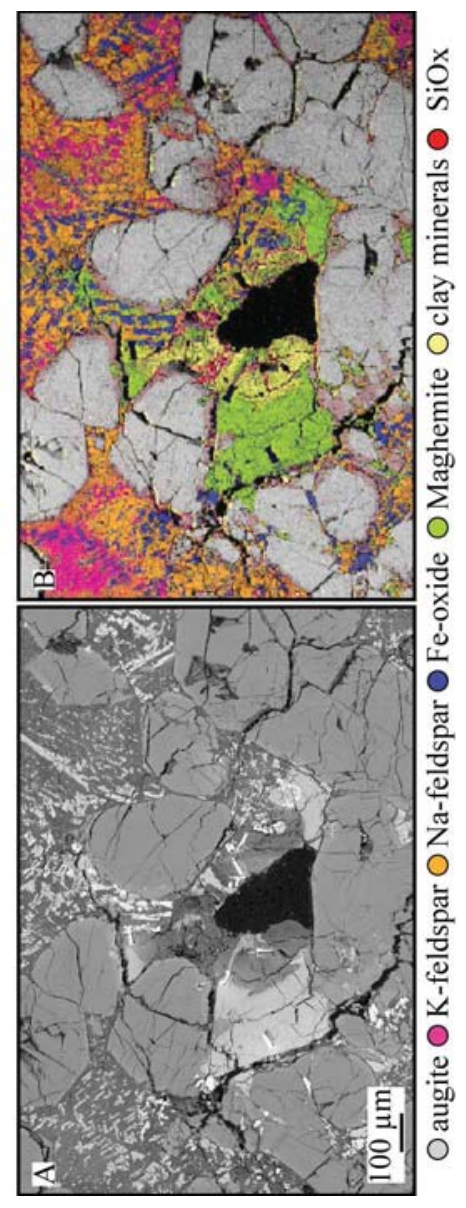




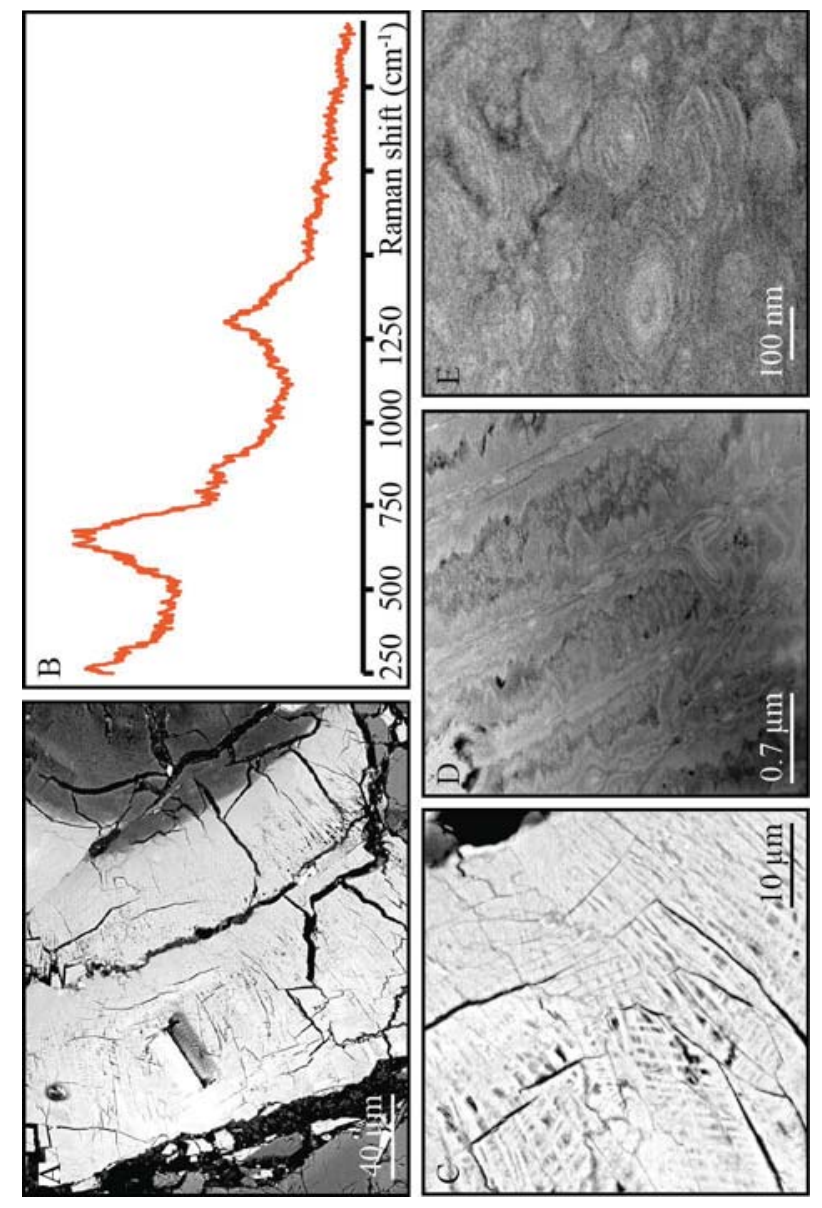



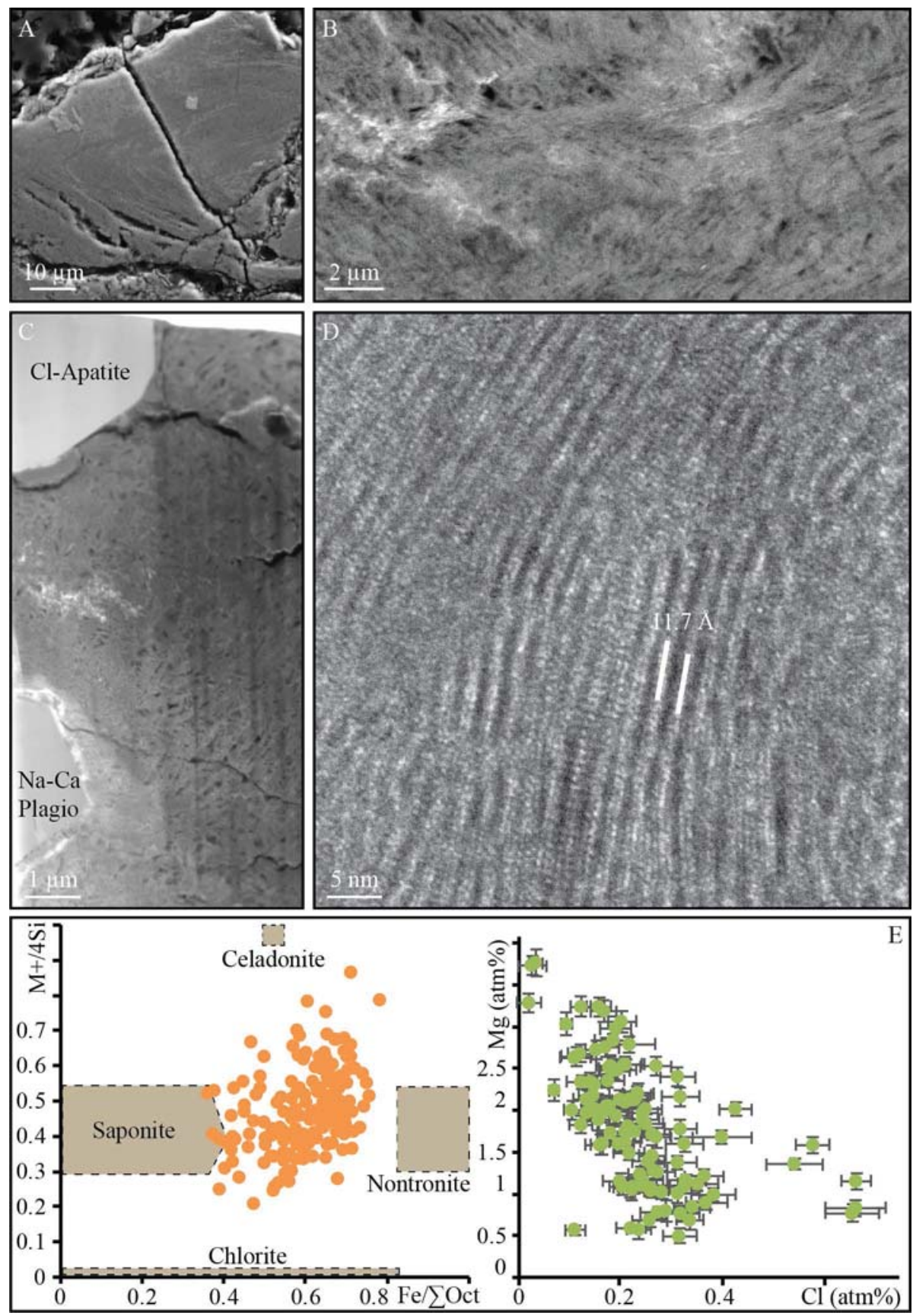

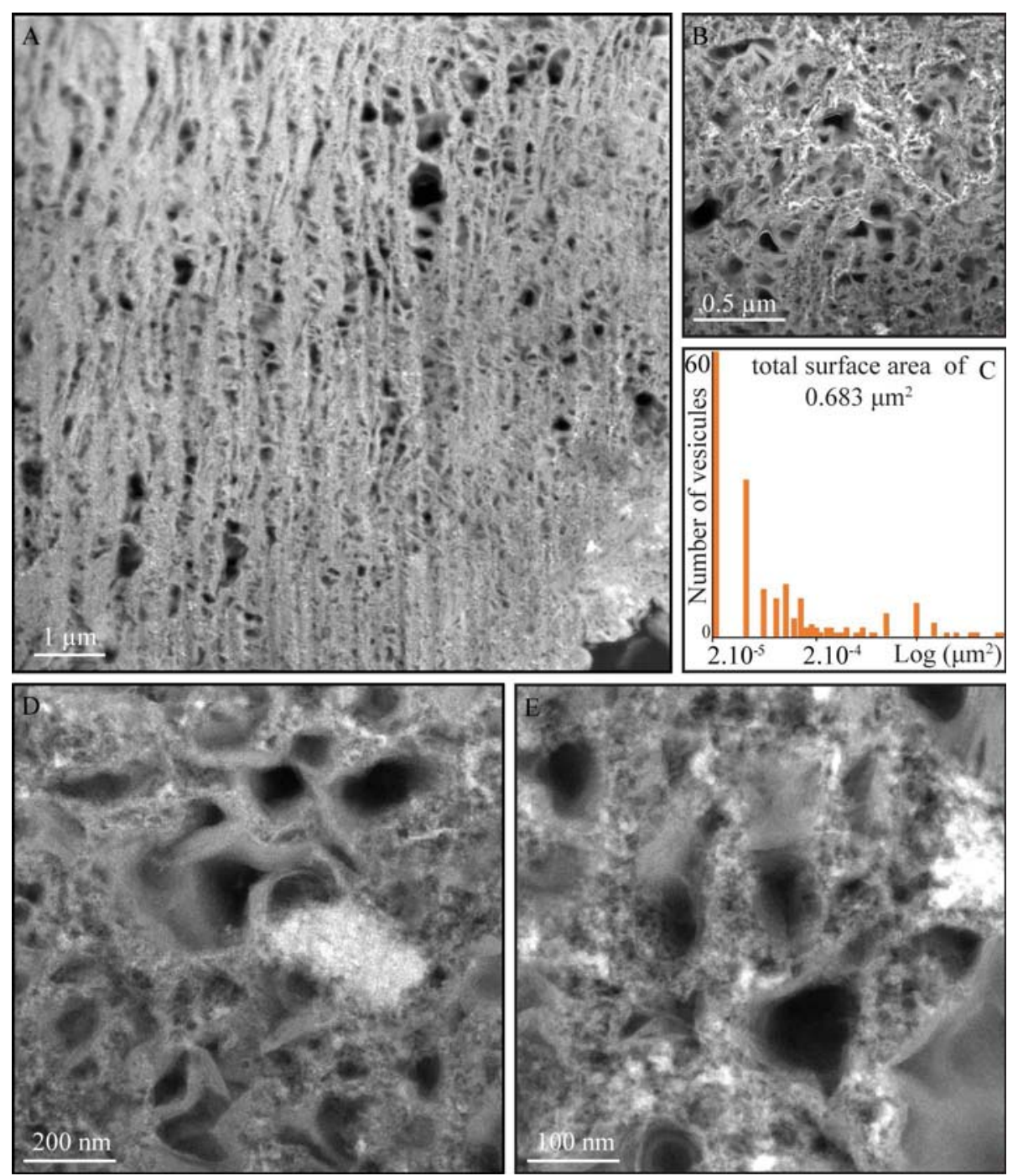